\title{
Nurse practitioner prescribing: an international perspective
}

This article was published in the following Dove Press journal:

Nursing: Research and Reviews

30 October 2015

Number of times this article has been viewed

\section{Jacqueline Fong 1,2 \\ Thomas Buckley² \\ Andrew Cashin ${ }^{3}$}

'St George Hospital, Kogarah, ${ }^{2}$ Sydney Nursing School, University of Sydney, Camperdown, NSW, Australia; ${ }^{3}$ School of Health and Human Sciences, Southern Cross University, Lismore, NSW, Australia
Correspondence: Jacqueline Fong Sydney Nursing School, University of Sydney, Level 4, Building MO2, Camperdown NSW 2006, Australia Tel +6I 291144227

Fax +6I 293510615

Email jacqui.fong@sydney.edu.au
Background: Internationally, the delivery of care provided by nurses and midwives has undergone a significant change due to a variety of interrelated factors, including economic circumstances, a diminishing number of medical providers, the unavailability of adequate health care services in underserved and rural areas, and growing specialization among the professions. One solution to the challenges of care delivery has been the introduction of nurse practitioners (NPs) and the authorization of NPs to prescribe medicines.

Aim: The aim of this paper was to review the current international literature related to NP prescribing and compare the findings to the Australian context. The review focuses on literature from the United States, Canada, Europe, Australia, and New Zealand.

Methods: Databases were searched from January 2000 to January 2015. The following keywords: "nurse practitioner", "advanced nurse", "advanced practice nurse", "prescri*", "Australia", "United States America", "UK", "New Zealand”, "Canada", "Europe”, "drug prescri*", "prescri* authority", and "prescri* legislation" were used.

Findings: NPs tend to prescribe in differing contexts of practice to provide care in underserved populations and require good systems literacy to practice across complex systems. The key themes identified internationally related to NP prescribing relate to barriers to prescribing, confidence in prescribing, and the unique role of NPs in prescribing medicines, eg, the high prevalence of prescribing pain medicines in several countries, including Australia.

Conclusion: Across all countries reviewed, there appears a need for further research into the organizational and financial conditions/climate in which NPs prescribe. Such research may give a better understanding of not only NP's true prescribing capacity currently but also inform future NP prescribing policy.

Keywords: nurse practitioner, prescribing

\section{Introduction}

Internationally, the delivery of care provided by nurses and midwives has undergone a significant change due to a variety of interrelated factors, including economic circumstances, a diminishing number of medical providers, the unavailability of adequate health care services in underserved and rural areas, and growing specialization among the professions. ${ }^{1,2}$ One solution to the challenges of care delivery has been the introduction of nurse practitioners (NPs). The implementation of NPs serves to improve access to treatment; provide cost-effective care; target at-risk populations; provide outreach services in all settings but in particular outer metropolitan, rural, and remote communities; and provide mentorship and clinical expertise to other health professionals. ${ }^{3}$ The International Council of Nurses defines NPs as registered nurses 
(RNs), who, through experience and formal education (typically master level), have acquired an expert knowledge base, complex decision-making skills, and the necessary clinical competencies for expanded practice. ${ }^{4}$ The characteristics of this practice are shaped by the context and country in which the NP practices. $^{4}$

NPs' roles were first introduced in the USA in the 1960s as a way of meeting demand for health services in the community. ${ }^{5}$ Since then, the NP role (or equivalent) has been introduced in a number of other countries, including the UK, Australia, New Zealand (NZ), Canada, and mainland Europe (including Sweden, the Netherlands, and Finland). ${ }^{6,7}$ In Australia, the NP role was first introduced into the health care context in 1998, with prescriptive authority commencing in some jurisdictions in $2001 .{ }^{8}$

In Australia, the title NP is protected by legislation, and NPs have the capability to provide high levels of clinically focused nursing care in a variety of contexts. ${ }^{9}$ One of the key aspects in which the scope of NPs differs from other RNs is the prescriptive authority, or the legal privilege to prescribe medications. Endorsed NPs in Australia are authorized to prescribe medications relevant to their scope of practice. ${ }^{10,11}$ Prescribing has been defined as an iterative process involving the steps of information gathering, clinical decision-making, communication, and evaluation, which results in the initiation, continuation, or cessation of medications. ${ }^{12}$ A prescriber is defined as a health practitioner authorized to undertake prescribing within the scope of their practice. ${ }^{13,14}$

\section{Aim}

The aim of this review was to evaluate the current international literature related to NP prescribing and to compare the findings to the Australian context. This review focused on literature from USA, Canada, Europe, NZ, and Australia. This review focused on these specific countries, that have health systems that are comparable with the Australian health system. This review encompassed the legislation/regulations and educational preparation related to NPs prescriptive authority across the various settings.

\section{Methods}

A literature review was undertaken using permutations of the following keywords: "nurse practitioner", "advanced nurse", "advanced practice nurse", "prescri*", "Australia", "United States America”, "UK”, "New Zealand”, “Canada”, "Europe", "drug prescri*”, "prescri* authority", and "prescri* legislation". Databases were searched from January 2000 to January 2015. The search was limited to publications from the year 2000 onward, a time when NPs were first introduced in Australia. Databases searched include PsycINFO, PubMed, CINAHL, and MEDLINE. Only papers published in English were included.

Articles were included in the review only if they reported specifically in relation to NP prescribing practices. A search of literature from European countries was conducted to identify if legislation existed to enable NP authorization and NP prescribing. In reference to the UK literature the title NP is not a legislated title, but refers to a position scope, which may include prescribing medicines. Literature related to authorized independent nurse prescriber's, who are frequently employed in NP positions, was reviewed and discussed in this context. This literature was included to ensure the review encompassed new and emerging models of NP prescribing and also identify legislative differences among countries related to NP prescribing.

\section{Search results}

Using this search strategy, 406 references were identified. Of the 406 articles, 296 articles were excluded through review of

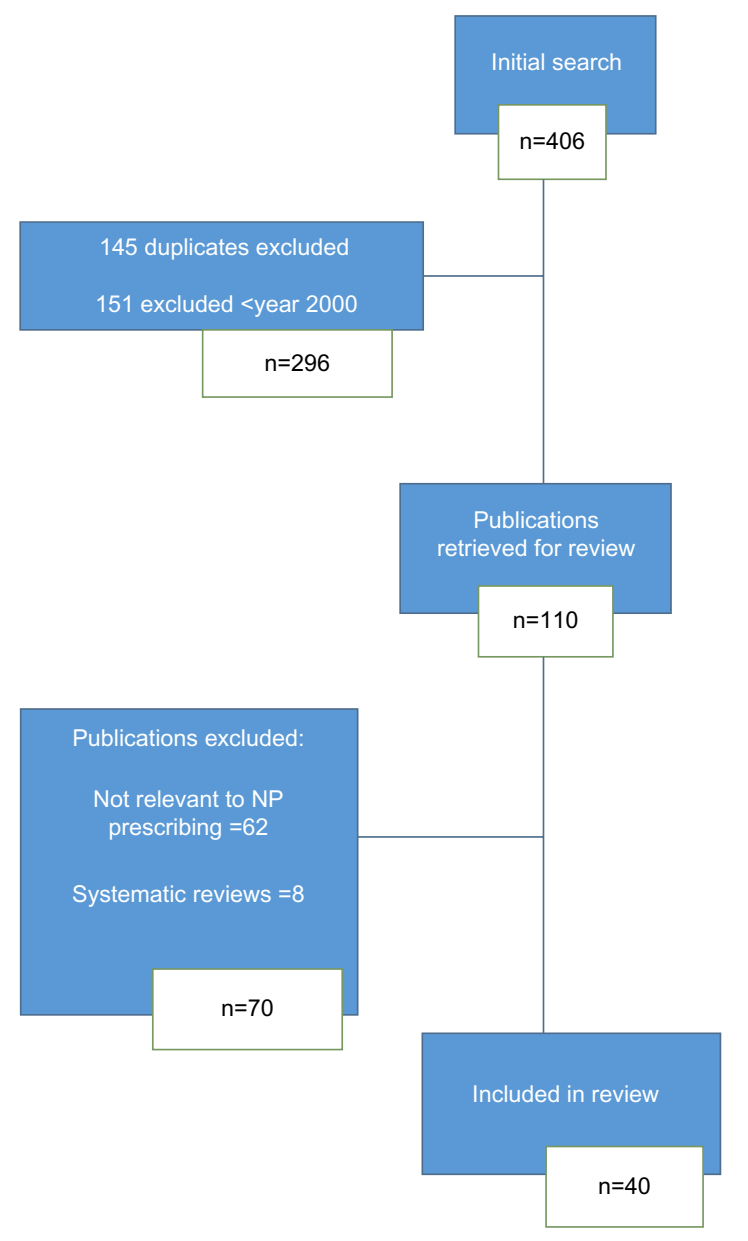

Figure I Search strategy.

Abbreviation: NP, nurse practitioner. 
abstracts, including 145 duplicates removed. Full texts of the remaining 110 articles were obtained. A further 70 articles were excluded as they did not meet the criteria pertaining to NP prescribing practices in the specific countries reviewed. Non-English and systematic reviews and other integrative review papers were also not selected, leaving 40 articles selected for the review (Figure 1). Surveys or questionnaires were the most commonly used method $(n=20)$, followed by focus groups/interviews/expert panel review $(n=10)$, retrospective designs $(n=5)$, audits $(n=4)$, and one randomized control trial $(\mathrm{n}=1)$.

\section{USA}

Nurse prescribing has been in place in the USA since the 1960 s, with the purpose of reducing the workload of physicians and addressing the needs of patients in remote areas. ${ }^{15}$ Nurse and midwife prescribing has evolved in the USA out of the establishment of the advanced practice roles such as NP, physician assistants (PAs), and nurse-midwife. ${ }^{16}$ NPs were granted prescriptive privileges in 1969, when initially legislation was introduced to allow NPs to prescribe medications under the rules and regulations of the regulatory Boards of Medicine and Nursing and was limited to a dependant/ collaborative arrangement. ${ }^{17}$ By 2005, 13 states and the District of Columbia authorized NPs to independently prescribe, including controlled drugs. ${ }^{17}$ This involved state-mandated requirements for collaborative practice arrangements, between the NP and medical practitioner. ${ }^{17}$ There are now 21 states in America deemed to have full practice authority. This authority includes prescriptive authority without mandated collaborative arrangements. ${ }^{17}$

To obtain licensure in the USA as an NP, candidates must hold a master's degree, a post-master's certificate, or a doctoral degree in nursing from an accredited program. There is a move toward a full requirement for a doctorate as the entry level qualification. ${ }^{18,19}$ Generally, NPs are licensed by the Board of Nursing for the state in which they will practice; laws differ depending on the state. Depending on each state's regulations, licenses must be periodically renewed, with some states requiring continuing education in order to renew licenses. ${ }^{17}$

Although NPs have had prescriptive authority for some time, surprisingly, there is limited research published regarding patient outcomes of NP prescribing practice in the USA. Hooker and Cipher $^{16}$ studied the prescriptive practices of NPs, PAs, and medical practitioners by analyzing data from The National Ambulatory Medical Care Survey and found that NPs wrote significantly more prescriptions in rural areas when compared to PAs and medical practitioners. It was proposed that this may relate to more primary care NPs being located in nonmetropolitan areas compared to the number of physicians in these areas. There is no significant difference found in antibiotic prescribing by NPs compared to medical practitioners in a retrospective study of data from the National Hospital Ambulatory Medical Care Survey and the National Ambulatory Medical Care Survey between 1997 and 2001, which investigated NPs $(n=506)$ and medical practitioners $(n=13,692)$ prescribing for upper respiratory infections. $^{19}$

It appears that in the elderly, the most commonly prescribed drugs by NPs in the USA include antihypertensive drugs, analgesics, cardiovascular drugs, and diabetic medications. ${ }^{20}$ In the 2004 AANP National Nurse Practitioner Sample Survey, a survey of 16,543 NPs identified that the most commonly prescribed medications were nonsteroidal anti-inflammatory drugs (NSAIDs) and antibiotics followed by antihypertensive medications, diabetic medications, contraceptives, and bronchodilators. ${ }^{21}$ This study reported that NPs routinely prescribe in all 50 states and in the District of Columbia, as well as in all practice settings, regardless of specialty. ${ }^{21}$ The types of medications prescribed in the USA support the notion that NPs employ pharmacotherapy in the management of acute and complex chronic conditions as well as health maintenance and diseases prevention. ${ }^{20-22}$ Studies that compared NP's prescribing practices with other clinicians demonstrated the principal finding that there is no difference between NP and medical practitioners prescribing practices. ${ }^{19-21}$

\section{Europe}

In mainland European countries, some nurses have prescriptive authority, although this varies among specific European countries. Sweden has had prescriptive authority for nurses since 1994, whereas the Netherlands and Spain have explored legislative and procedural amendments to allow prescriptive authority. ${ }^{23}$ The Finnish Government has also proposed that nurses working in national public health centers are given a limited right to prescribe medication to patients in their care. ${ }^{23-25}$ Nurse prescriptive authority was primarily implemented in Europe for similar reasons to the USA to improve the patient's access to medicines, in particular for those in remote areas to both supplement the shortage of physicians and reduce the work load of medical practitioners. ${ }^{25,26}$

In many European countries, NPs have been practicing in the health care system for years, although the level of education can vary between countries and even within the states 
or territories within single countries. ${ }^{27,28}$ The divergence and reasons for nurse prescribing are reflected in the nonuniform qualification requirements, the training they receive, and differences in regulation of practice among each European country. ${ }^{23}$ The general standard appears to be that nurses must have substantial clinical experience and undergo specific training as regulated by each country's regulatory body to prescribe medications. ${ }^{23}$ No published studies related to outcomes of NP prescribing from European countries were identified.

Since the late 1990s, the UK has seen a major expansion in the scope of nurse prescribing, which reflects changes in government policy over this time. ${ }^{29}$ In the UK, NP is not a legislatively protected title, and registered independent nurse prescribing policy enables RNs to prescribe within the RN's scope of practice. Due to the lack of regulation of NPs in the $\mathrm{UK}$, prescribing is encompassed in the literature under the banner of independent nurse prescribing. Further changes in the legislation in May 2006 radically altered the professional restrictions on prescribing: ${ }^{29,30}$ enabling independent nurse prescribers to prescribe any licensed medicine on the British National Formulary, for any medical condition within the RN's scope of practice. ${ }^{31}$ This put nurses on par with medical practitioners in relation to prescribing privileges in the UK. In addition to independent prescribers, supplementary prescribing is another form of nurse prescribing in the UK, based on a voluntary prescribing partnership between a medical practitioner (independent prescriber) and a nurse (supplementary prescriber). In this relationship, the supplementary prescriber has the ability to prescribe any drug in a patientspecific clinical management plan once the patient has been diagnosed by the medical practitioner. ${ }^{32}$ The initial education and training for nurse prescribers began in the mid $1990 \mathrm{~s}^{32} \mathrm{To}$ qualify as a supplementary prescriber, nurses undertake a recognized Nursing and Midwifery Council (NMC) accredited prescribing course through a university, and upon successful completion, they register with the NMC. ${ }^{31}$ Since 2004, all nurses who complete the NMC qualification can prescribe independently as well as in a supplementary capacity. ${ }^{31,33} \mathrm{At}$ present, the UK nursing regulator will only accept practitioners who are qualified through UK universities, which follows the NMC curriculum. ${ }^{31}$ The lack of processes to determine equivalency for international applicants wishing to work in the UK is an issue in terms of mobility of the international NP workforce.

The education and training for independent nurse prescribers in the UK consist of a standalone course of 26 days of theory and 12 days of mentored practice. ${ }^{29}$ In a national survey of independent nurse prescribers conducted in 2003 by Latter et al, the self-reported perception of adequacy of nurses' educational preparation for independent prescribing was evaluated $(n=285$, response rate $=71 \%)$. ${ }^{33}$ The finding from this national survey highlighted that the majority of nurses considered that the initially taught course elements of their education program met prescriber needs to some extent (61\%) or completely (22\%), although a small minority was less that satisfied with the program as preparation for prescribing.

In the literature related to nurse prescribing in the UK, three key themes have been identified: barriers to prescribing, confidence in prescribing, and appropriateness of prescribing practices. Latter and Courtenay ${ }^{34}$ identified that patients generally reported positive experiences with nurse prescribing, particularly in relation to issues of convenience, and the fact that medication is prescribed by the practitioner with whom they have a professional relationship. This study evaluated independent nurse prescribers working in a primary care setting reporting that the majority of nurse prescribers had greater perceived autonomy and enhanced job satisfaction. ${ }^{34}$ Another study reported that one of the main benefits of prescribing was nurses' ability to provide a complete streamlined continuity of care, which allowed nurses the ability to do almost everything for the patient, from start to finish. ${ }^{35}$ In this study, investigators interviewed nurse prescribers between 2005 and 2006 to investigate the impact of prescribing in the UK. Participants reported that prescribing allowed them to overcome difficulties in the health care system that would otherwise delay patients' access to medicine and that becoming a prescriber provides benefits far in excess of generating prescriptions. ${ }^{35}$ Prescribing enhances nurses' ability to communicate with patients by increasing their knowledge of medicines and their confidence to discuss medications. This corroborated the survey by Latter and Courtenay, which reported that nurse prescribers provide patients with a good level of information. ${ }^{34}$

Nurses play a key role in hospital inpatient management of pain within the UK, and this is an area for which qualified nurse prescribers are known to prescribe medications. ${ }^{36}$ From a national questionnaire of nurse prescribers in pain management $(n=131$ with a response rate $=85 \%$ ), it was reported that prescribing was perceived to improve nurses' ability to promote evidence-based practice, but nurses were limited in prescribing controlled drugs. ${ }^{36}$ In this study, nurses reported that they were prevented by legislation from prescribing analgesics that were commonly used in their workplace, having to find a medical practitioner to prescribe 
the medication, which took time and caused frustration and confusion restricting their work. ${ }^{36}$ Removing this restriction would improve nurse's ability to provide pain management to all patients.

In a survey by While and Biggs of health visitors and district (community) nurses in three health trusts in England ( $n=91$, response rate $=71 \%$ ), two-thirds of nurse prescribers found that the current nurse prescriber's formulary did not cover their prescribing needs, which hindered their prescribing practices. ${ }^{37}$ However, this limitation on prescribing was later resolved with legislation that allowed nurse prescribers full access to the formulary. ${ }^{38}$

Research from the UK suggests that when nurses do prescribe, they do so within their areas of competence and according to specific guidelines. ${ }^{22}$ These findings were supported by a study of independent nurse prescribers in which an expert panel judged the appropriateness of prescribing decisions made during consultations. ${ }^{39}$ In this study, 25 nurse prescribers were presented with a number of prescribing scenarios, and $40 \%$ of the participants were able to identify the issues involved; however, the remaining participants were unable to identify the issues involved, suggesting that they would refer the patient to the general practitioner (GP) as these issues were outside their competence. ${ }^{39}$ This finding may lead us to believe that nurse prescriber's are aware of their own limitations when prescribing however this highlights the need for further research in measuring and determining prescribing practice outcomes for NPs and nurse prescriber's alike. This was further highlighted in a sample of UK accident and emergency and sexual health NPs in a review of case notes of 764 nurse prescribers. ${ }^{40}$ Both cohorts reported prescription of a wide range of medications from different drug groups, with analgesia and antibiotics being the most commonly prescribed treatments overall, from the 560 medications prescribed. In this study, $99.8 \%$ of prescribed medications were considered clinically appropriate for the patients presenting complaint, that suggests appropriate prescribing practice by NPs in these specialty areas. ${ }^{40}$

\section{Canada}

In the late 1960s in Canada, the introduction of the NP was the result of consciousness to formalize the changing roles of the nurse, movement toward specialization, and shortage of medical practitioners in all areas (urban and rural). ${ }^{41}$ At this time, although there was general recognition and need for the NP role, there was no official recognition of the role through formal legislation and regulation. In the 1970s, educational institutions began graduating NP students, but due to the lack of support by Canadian legislation and regulation, nurses remained registered as RNs even though some functioned in NP-like roles. ${ }^{41-43}$ This NP-like role was dependant on the collaborative arrangement and supervision of the medical practitioner especially in urban areas. ${ }^{42}$

By the 1980s, proposals for the formalization of NP role had faded due to a number of reasons, including an apparent oversupply of medical practitioners, weak support from policy makers, the absence of provincial/territorial legislation, and lack of public awareness of the NP role. ${ }^{41-43}$ In the 1990s, there was a shift in Canada's health care system with an increased focus in primary health care and this led to renewed pursuit in the NP role. This renewed interest in the NP role prompted the formal regulation and education of NPs within a defined scope of practice that was pursued by many provinces and territories. ${ }^{44}$ In Canada, assessment of competence for initial registration of an NP usually consists of proof of completion of an approved NP educational program and other requirements (eg, an examination) as determined by the jurisdiction. ${ }^{44}$ At present, NP programs are approved by the regulatory body at the jurisdictional level across Canada as well as assessment of evidence of continuing education for NP registration. ${ }^{44}$ By May 2005, eleven Canadian provinces and territories had NP legislation and regulations in place or in progress. ${ }^{42}$ Current legislation and regulation authorizes NPs to independently diagnose and treat health conditions, but prescribing authority appears to remain limited in some provinces. In November 2012, the federal government made changes to regulations under the Controlled Drugs and Substances Act that would enable NPs in Canada to prescribe controlled drugs and substances. ${ }^{42,44}$ Because health care is regulated by the provinces and territories in Canada, NPs in certain provinces are not able to prescribe these drugs as they do not have legislated authority to do so.

There appears little available published literature with regard to outcomes of NP prescriptive practices in Canada. One qualitative survey explored 16 NPs practice within an interdisciplinary model of pain management in long-term care, reporting that $94 \%$ of respondents prescribed nonopioid analgesics, such as acetaminophen (paracetamol) and aspirin, and nonpharmacological pain interventions. ${ }^{45}$ Sixty-two percent of participants reported prescribing NSAIDs and $12 \%$ reported prescribing opioid analgesics from a defined formulary; NPs themselves reported that restrictions to their scope of practice limited both the effectiveness and efficiency of their role in managing pain. Such restrictions were related to their inability to prescribe specific pain medications, particularly opioids. ${ }^{45,46}$ This study also highlighted 
the importance of a trusting relationship among health care team members, especially between NPs and medical practitioners to fully utilize patient care. ${ }^{46}$ This is supported by a number of other studies from elsewhere with reports that collaboration with medical practitioners can facilitate supportive relationships and continuous learning for NP prescribers in the management of acute and chronic pain if the collaboration is in the true sense and not a guise for medical gatekeeping. ${ }^{36,41,45}$

\section{New Zealand}

Nurse prescribing within NZ coincided with the development and implementation of the NP role following a recommendation of a key ministerial taskforce in $1999 .{ }^{47}$ Prior to July 2014, NPs could only prescribe from a set formulary of drugs, ${ }^{48}$ in an emergency for up to 3 days' dosages. Additionally, in NZ, it is possible to be registered as an NP but without prescribing privileges, and these NPs are registered as nonprescribing NPs and have a condition on their registration identifying this. ${ }^{49}$ From July 2014, changes to the Medicine Act 2013 enabled NPs with the authority to prescribe and the ability to prescribe all medicines appropriate to their scope of practice, rather than being limited to a predefined formulary. ${ }^{50}$

In NZ to register as an NP, the following qualifications are required.

Registration with the Nursing Council of New Zealand in the registered nurse scope of practice; a minimum of 4 years' experience in a specific area of practice; and the completion of an approved clinical master's degree program which includes demonstration of the competencies for advanced practice and prescribing applied within a defined area of practice of the nurse practitioner. The program must include relevant theory and concurrent practice; or the completion of an equivalent overseas clinically focused master's degree qualification which meets the requirement specified above; and passing an assessment by an approved panel against the nurse practitioner competencies [page 2]. ${ }^{49}$

In NZ, the Nursing Council of New Zealand assesses competence to identify medical problems and diagnoses, action planning, and prescribing prior to approving NP prescribing. ${ }^{49}$ Every 3 years, prescribing NPs are required to provide evidence that they have maintained competence. This evidence includes ongoing peer review of their prescribing practice by an authorized prescriber and a minimum of 40 hours per year of professional development and a minimum of 40 days per year of ongoing nursing practice over a 3-year period within their defined area of practice. $^{49}$
Two studies that pertained to the NP prescribing practices in NZ give insight into NP prescribing practices. ${ }^{51,52}$ The perceptions of GPs regarding the NP role is reported in one study where GPs favorably viewed NP functions traditionally associated with nursing such as health, teaching, home visiting, obtaining health histories, and taking part in evaluation of care but less favorably viewed NP prescribing, ordering laboratory tests, and physical assessment. ${ }^{52}$ This study by Mackay surveyed 108 GPs (response rate $=46.3 \%$ ) in the Northland District Health Board of New Zealand. The GPs expressed concerns in nurses encroaching on what have traditionally been medical functions such as prescribing, undertaking physical examinations, and ordering laboratory tests. In another study of critical care NPs, conducted between 2006 and 2008, the frequency of prescribing and type of medications prescribed was audited with NPs prescribing more medications when authorized to prescribe independently, compared to when they had to use standing orders. ${ }^{51}$ This finding is not surprising but does highlight the need for outcome-based research on NP independent prescribing in the NZ context.

\section{Australia}

In Australia, the NP role was first introduced into the health care context in 1998, with prescriptive authority commencing in some jurisdictions in 2001. ${ }^{8}$ NPs in Australia are currently endorsed by two pathways: "Pathway 1 - applicants who have successfully completed a Board-approved Master's Degree (NP) course; Pathway 2 - applicants who have completed substantially equivalent Master's education that helps the applicant meet the competency standards for the NP" (page 1). ${ }^{53-55}$ Ongoing endorsement as an NP is contingent upon the NP meeting the Board's requirements for renewal of registration annually. NPs are required to make an annual statutory declaration that they have met requirements under section 109 of the National Law, including completion of the required continuing professional development and meeting the recency of practice requirements. ${ }^{9}$ This involves the annual requirement of 20 hours of continued professional development (CPD) to be undertaken by all RNs for general registration; NPs are required to undertake an additional 10 hours of specified CPD per year, and this CPD must be relevant to the NPs context of practice, and where appropriate, address: "prescribing and administration of medicines; diagnostic investigations and consultation and referral". 9

In 2007, it was reported that one-third of NPs surveyed specifically stated that they were still awaiting approval of 
formularies to prescribe medication. ${ }^{56}$ Since then, changes in state-level legislation for prescribing practices for NPs have addressed some of these barriers. For instance, in New South Wales (NSW), where the largest proportion of Australian NPs practice, since May 2012 NSW Health has an approved formulary from which NPs in the public service can prescribe. ${ }^{57}$ This change resulted in NP prescribers not having to have a separate formulary approved at the local institution level, unless additional drugs not listed on the NSW NP formulary are to be prescribed. ${ }^{57}$ However, this is not the case in every Australian State or territory where local agreements are sometimes required or limitations on drug formulary exist. ${ }^{58}$ Private practice NPs are required to submit a separate formulary, appropriate to their scope of practice for approval to the Chief Nursing and Midwifery Officer in the state of NSW, a practice also required in the majority of other Australian states. ${ }^{57}$ Additionally, private sector NPs are only eligible to access the Pharmaceutical Benefits Scheme (PBS) and Medical Benefits Scheme (MBS) working within a collaborative arrangement. ${ }^{59}$

In a study by Khanal et al, students enrolled in an NP Master's course were less confident than medical and pharmacy students in relation to their clinical judgment when choosing medicines in relation to an online case study prescription, although the correctness in choice of medicines by NP participants was no different to their medical and pharmacy colleagues. ${ }^{60}$ This study measured the student's degree of certainty of their answers; it reported that pharmacy students were the most confident compared to medical and NP students. ${ }^{61}$ Despite being the least confident in their answers, this may not necessarily be a negative finding and may suggest NP student participants demonstrate more caution when prescribing. Indeed, confidence in prescribing is highlighted in another Australian study of NPs where participants were the most confident providing their clients with education about medicines but were less confident adjusting medications prescribed by others or discontinuing medicines prescribed by others. ${ }^{62}$ Unsurprisingly, in this study of 251 participants, the more experienced the NP was, the greater their confidence in meeting legal requirements for prescribing. ${ }^{62}$

Data from this same Australian survey of NP prescribing practices also revealed the unique role of NPs in managing infective process and pain management, ${ }^{63}$ with anti-infectives and analgesics the most frequently prescribed classification of medications, a finding consistent with the international literature. ${ }^{20,21,40,64}$ Of the respondents surveyed in this study, it is notable that $>50 \%$ worked in emergency and/or acute care settings with the finding of analgesics; the second most common drug prescribed perhaps is reflective of the unique role of NPs managing pain in both chronic and acute settings. ${ }^{63}$ However, similar to many other countries mentioned in this review, there remains a lack of published Australian studies related to patient outcomes from NP prescribing.

\section{Discussion}

A critical analysis in the literature from the USA, Canada, UK, Europe, and NZ revealed three key themes: types of medications prescribed, barriers to prescribing practice, and confidence-related prescribing practice.

\section{Types of medications prescribed}

There are a few research reports in the international literature related to the actual medications prescribed by NPs in the treatment of their patients. Reports from the USA, ${ }^{20,21}$ Canada, ${ }^{45} \mathrm{NZ}^{50,51}$ (in a critical care setting), and $\mathrm{UK}^{40}$ (emergency care setting) have suggested that the most commonly prescribed medications are analgesics, antihypertensives, and antimicrobials. This compares to Australian NPs prescribing practices where research has suggested that the most commonly prescribed medications are analgesics and anti-infective drugs. ${ }^{63}$ Interestingly, NP prescribing of antihypertensive medications does not appear as prevalent in Australia as elsewhere, possibly due to the fact that $\sim 90 \%$ Australian NPs practice in hospital settings, mostly in emergency and acute care settings, unlike the USA where the majority appear to practice in primary care settings. ${ }^{18-21}$ However, comparison is complicated by the reports that medicines prescribed are often specialty-specific, and reinforces the need for further research to establish, compare, and contrast NP prescribing practices and outcomes by specialties across comparable countries.

\section{Barriers to prescribing}

A consistent theme across the literature is related to barriers to prescribing practices, which can lead to clinician frustration and potential deficits in patient care delivery. For example, in the UK, reports suggested that nurse prescribers were limited in the prescribing of controlled drugs for pain management, ${ }^{35}$ similar to reports from Canada. ${ }^{45}$ In Australia, reports suggest that NPs prescribing practice barriers have related to legislative and policy barriers, such as access to the PBS for subsidy of medicines prescribed. ${ }^{62}$ However, some of these barriers appear to be resolving over time internationally with UK prescribers granted access to the full British National Formulary in $2006^{29}$ and legislation in Australia enabling NP prescriptions to be eligible for PBS 
reimbursement. ${ }^{59}$ In contrast, barriers to prescribing were not an evident theme in the US literature, probably reflective of the longer duration of NP prescribing in the USA.

\section{Confidence in prescribing}

Confidence in aspects of prescribing was a theme evident in Australian, Canadian, and UK literature. ${ }^{39,40,46,62}$ The Australian literature suggested that NPs feel most confident in aspects of prescribing related to providing educational information and least confident altering others' prescriptions, with more experienced NPs reported greater confidence prescribing. ${ }^{62}$ Actual confidence in prescribing itself is not reported in the UK and Canadian literature. However, aspects of confidence in prescribing could perhaps be interpreted in the reported studies ${ }^{39,40}$ as pertaining to the areas of competence and specific guidelines in which NPs prescribe. Canadian studies identified the key factor of the importance of collaborative relationships. ${ }^{45,46}$ These relationships can be viewed to perhaps enhance the NPs confidence in prescribing with the development of a trusting relationship with medical practitioners. A study from the $\mathrm{UK}^{36}$ reported that collaboration with medical practitioners facilitated a supportive relationship, allowing continuous learning for nurse prescribers in the aspects of prescribing. ${ }^{45,46}$ Collaborative relationships among health care team members are key for NPs in their ability to effectively and safely prescribe. Further research is needed to explore the link between NP confidence and quality use of medicines to determine if confidence is appropriately related to safe and effective prescribing in clinical practice.

\section{Theme not identified in Australian literature}

The main theme that was not prevalent in the Australian literature was assessment of NPs prescribing practice. US literature focused on comparative outcomes of NPs with medical practitioners and PAs on their prescriptive patterns, ${ }^{16,19,21,22}$ UK studies focused on clinical appropriateness and safety of prescribing, ${ }^{33-38,40}$ also evident in NZ ${ }^{50,51}$ and Canadian literature. ${ }^{41,45,46}$ In comparison, there have not been any Australian studies to date measuring outcomes of NP prescribing, which may be attributed to the infancy of Australian NP prescribing compared to the USA.

\section{Implications for further research into NP prescribing}

Across all the countries reviewed, there appears a need for further research into the organizational and financial conditions/climate in which NPs prescribe. NPs tend to practice in differing contexts, requiring systems literacy to deliver care across complex systems. ${ }^{65}$ Such research may give a better understanding of not only NP true prescribing capacity but also inform future NP prescribing policy. Additionally, there is a growing need across all the countries reviewed to conduct research to determine the true impact of NP prescribing on both patient outcomes and health service outcomes, especially in countries such as Australia where NP prescribing is now quiet prevalent and many historical barriers to prescribing remain to overcome.

\section{Limitations}

A potential limitation of this review is that in keeping the focus of the review to published peer reviewed literature, some gray literature and policy documents may have potentially been excluded from the review that may report outcomes of NP prescribing. However, the authors believe that such literature should be subject to peer review to be included and inform the discussion of the current state of NP prescribing outcomes. Another limitation to the review may be the selection of articles in the UK arena, as in the UK, NP is not a legislatively protected title, and registered independent nurse prescribing policy enables RNs to prescribe within the RN scope of practice. Due to the lack of regulation of NPs in the UK, prescribing is encompassed in the literature under the banner of independent nurse prescribing. However, this is acknowledged in the review discussion regarding UK NP prescribing.

\section{Conclusion}

The introduction of NP prescribing internationally has come about due to the diversity of external and internal forces, although the main driver appears to be the health care needs of underserviced populations. The nature of the legislation, educational preparation, and regulations that allows NPs prescriptive authority varies considerably between countries, although additional education and preparation are required at a postgraduate or postregistration level in all the countries reviewed.

Australian NP prescribing is still relatively new in its development when compared to an international perspective, although legislation relating to NP prescribing now appears similar in nature to comparative health systems. Additionally, medications prescribed by NPs throughout the reviewed countries does not differ greatly when compared to Australian NPs practices. It is apparent that there is a lack of evidence-based research on actual outcomes to NP prescribing practices throughout the countries reviewed. The review highlights the need for further research 
to both evaluate the uniqueness of NP prescribing in differing and sometimes complex contexts and also to evaluate the true impact on both patient and system outcomes across all countries. With the changing face of medicine, this review highlights the barriers that need to be addressed with further research, such as lack of jurisdictional legislation in all countries, allowing NPs to prescribe to their full potential.

\section{Disclosure}

The author and coauthors declare that they have no relevant or material financial interests that relate to the research described in this paper.

\section{References}

1. Kroezen M, van Dijk L, Groenewegen PP, Francke AL. Knowledge claims, jurisdictional control and professional status: the case of nurse prescribing. PLoS One. 2013;8(10):e77279.

2. Creedon R, O'Connell E, McCarthy G, Lehane B. An evaluation of nurse prescribing. Part 1: a literature review. Br J Nurs. 2009;18(21): 1322-1327.

3. Australian Nursing and Midwifery Federation. Fact sheet: A Snapshot of Nurse Practitioners in Australia; 2012 [cited April 24, 2015]. Available from: http://anmf.org.au/documents/reports/Fact_Sheet_Snap_Shot_ Nurse_Practitioners.pdf. Accessed April 24, 2015.

4. International Council of Nurses. Definition and Characteristics for Nurse Practitioner/Advanced Practice Nursing Roles [official position paper]; 2009. Available from: https://acnp.org.au/sites/default/files/33/ definition_of_apn-np.pdf. Accessed April 23, 2015.

5. Foster J. A History of the Early Development of the Nurse Practitioner role in New South Wales, Australia. Research Gate; 2010. Available from: http://www.researchgate.net/publication/259239301. Accessed April 15, 2015

6. Pulcini J, Jelic M, Gul R, Loke A. An international survey on advanced practice nursing education, practice, and regulation. J Nurs Scholarsh. 2010;42(1):31-39.

7. Kroezen M, Francke AL, Groenewegen PP, van Dijk L. Nurse prescribing of medicines in Western European and Anglo-Saxon countries: a survey on forces, conditions and jurisdictional control. Int J Nurs Stud. 2012;49(8):1002-1012.

8. Dunn SV, Cashin A, Buckley T, Newman C. Nurse practitioner prescribing practice in Australia. J Am Acad Nurse Pract. 2010; 22(3):150-155.

9. Nursing and Midwifery Board, Australia. Guidelines on Endorsement as a Nurse Practitioner; 2013 [updated May 8, 2013; cited April 17 2015]. Available from: http://www.nursingmidwiferyboard.gov.au/ Registration-and-Endorsement/Endorsements-Notations/Guidelineson-endorsement-as-a-nurse-practitioner.aspx. Accessed April 17, 2015.

10. Dragon N. Leaving the paper trail behind. Aust Nurs J. 2008; 16(1):22-25.

11. Australian Government Department of Human Services Medicare. Nurse Practitioners and Midwives; 2010 [updated May 29, 2014; cited April 17, 2015]. Available from: http://www.medicareaustralia.gov. au/provider/other-healthcare/nurse-midwives.jsp. Accessed April 17, 2015.

12. Nissen L, Kyle G. Non-medical prescribing in Australia. Aust Presc. 2010;33(6):166-167.

13. NPS. Better Choices, Better health. Competencies Required to Prescribe Medicines: Putting Quality Use of Medicines into Practice. Sydney: National Prescribing Service Limited; 2012.Available from: ttps://www.nps.org.au/_ data/assets/pdf_file/0004/149719/Prescribing_Competencies_Framework. pdf. Accessed April 4, 2015.
14. Nissen L, Kyle G, Stowasser D, et al. Non-Medical Prescribing. An Exploration of Likely Nature of, and Contingencies for, Developing $A$ Nationally Consistent Approach to Prescribing by Non-Medical Health Professionals. Queensland, Australia: The National Health Workforce Taskforce and Price Waterhouse Cooper; 2010.

15. Ball J. Implementing Nurse Prescribing: An Update Review of Current Practice Internationally. Geneva: International Council of Nurses; 2009.

16. Hooker RS, Cipher DJ. Physician assistant and nurse practitioner prescribing: 1997-2002. J Rural Health. 2005;21(4):355-360.

17. American Association of Nurse Practitioners. State Practice Environment; 2013 [updated May 12, 2015; cited October 18, 2013]. Available from: http://www.aanp.org/images/documents/state-leg-reg/ stateregulatorymap.pdf. Accessed April 17, 2015.

18. Tuaoi LA, Cashin A, Hutchinson M, Graham I. Nurse practitioner preparation: is it time to move beyond masters level entry in Australia? Nurse Educ Today. 2011;31(8):738-742.

19. Ladd $\mathrm{E}$. The use of antibiotics for viral upper respiratory tract infections: an analysis of nurse practitioner and physician prescribing practices in ambulatory care, 1997-2001. J Am Acad Nurse Pract. 2005; 17(10):416-424.

20. Kennedy-Malone L, Fleming ME, Penny J. Prescribing patterns of gerontological nurse practitioners in the United States. J Am Acad Nurse Pract. 2008;20(1):28-34.

21. Goolsby MJ. 2004 AANP national nurse practitioner sample survey, part II: nurse practitioner prescribing. J Am Acad Nurse Pract. 2005;17(12):506-511.

22. Cipher DJ, Hooker RS, Guerra P. Prescribing trends by nurse practitioners and physician assistants in the United States. J Am Acad Nurse Pract. 2006;18(6):291-296.

23. Health Action International Europe. The Next Chapter in Promotion to Healthcare Professionals: Nurse Prescribers; 2011 [cited April 17, 2015]. Available from: http://haieurope.org/wp-content/ uploads/2012/02/27-July-2011-HAI-Europe-Nurse-PrescribersFactsheet.pdf. Accessed April 17, 2015.

24. National Health Service Scotland. Guidance for Nurse Independent Prescribers and for Community Practitioner Nurse Prescribers in Scotland: A Guide for Implementation. Edinburgh: Scottish Executive; 2006. Available from: http://www.gov.scot/resource/doc/145797/0038160.pdf. Accessed April 27, 2015.

25. Kroezen M, van Dijk L, Groenewegen PP, Francke AL. Nurse prescribing of medicines in Western European and Anglo-Saxon countries: a systematic review of the literature. BMC Health Serv Res. 2011;11:127.

26. Creedon R, O'Connell E, McCarthy G, Lehane B. An evaluation of nurse prescribing. Part 1: a literature review. Br J Nurs. 2009; 18(21): 1322-1327.

27. Fleming E, Carberry M. Steering course towards advanced nurse practitioner: a critical care perspective. Nurs Crit Care. 2011;16: 67-76.

28. Williamson S, Twelvetree T, Thompson J, Beaver K. An ethnographic study exploring the role of ward-based advanced nurse practitioner in acute medical setting. J Adv Nurs. 2012;68:1579-1588.

29. Avery AJ, James V. Developing nurse prescribing in the UK. BMJ. 2007;335(7615):316.

30. Stephenson T. Implications of the Crown Report and nurse prescribing. Arch Dis Child. 2000;83(3):199-202.

31. Department of Health United Kingdom. Nurse Independent Prescribing; 2010. Available from: http://webarchive.nationalarchives gov.uk/20130107105354/http://www.dh.gov.uk/en/Healthcare/ Medicinespharmacyandindustry/Prescriptions/TheNon-MedicalPre scribingProgramme/Nurseprescribing/index.htm. Accessed April 24, 2015.

32. Royal College of Nursing. RCN Fact Sheet: Nurse Prescribing in the $U K ; 2012$ [cited April 24, 2015]. Available from: http://www.rcn.org. uk/_data/assets/pdf_file/0008/443627/Nurse_Prescribing_in_the_ UK_-_RCN_Factsheet.pdf. Accessed April 24, 2015. 
33. Latter S, Maben J, Myall M, Young A. Evaluating nurse prescribers' education and continuing professional development for independent prescribing practice: findings from a national survey in England. Nurse Educ Today. 2007;27(7):685-696.

34. Latter S, Courtenay M. Effectiveness of nurse prescribing: a review of the literature. J Clin Nurs. 2004;13(1):26-32.

35. Bradley E, Nolan P. Impact of nurse prescribing: a qualitative study. J Adv Nurs. 2007;59(2):120-128.

36. Stenner KL, Courtenay M, Cannons K. Nurse prescribing for inpatient pain in the United Kingdom: a national questionnaire survey. Int J Nurs Stud. 2011;48(7):847-855.

37. While AE, Biggs KS. Benefits and challenges of nurse prescribing. J Adv Nurs. 2004;45(6):559-567.

38. Jackson A, Carberry M. The advance nurse practitioner in critical care: a workload evaluation. Nurs Crit Care. 2014;20(2):71-77.

39. Offendry M, Kendall S, Goodman C. The use of cognitive continuum theory and patient scenarios to explore nurse prescribers' pharmacological knowledge and decision-making. Int J Nurs Stud. 2007; 45(6):855-868.

40. Black A. Non-medical prescribing by nurse practitioners in accident and emergency and sexual health: a comparative study. J Adv Nurs. 2013;69(3):535-545.

41. Donald F, Martin-Misener R, Bryant-Lukosius D, et al. The primary healthcare nurse practitioner role in Canada. Nurs Leadersh. 2010; 23(Special Issue):88-113.

42. Canadian Nurses Association. The Regulation and Supply of Nurse Practitioners in Canada Ontario; Canadian Institute for Health Information; 2005. Avaliable from: http://www.npnow.ca/docs/techreport/section4/06_HHR_AppendixE.pdf. Accessed April 27, 2015.

43. College of Nurse of Ontario. FAQs: Nurse Practitioner Practice Questions; 2014 [updated December 15, 2014; cited April 13, 2015 ]. Available from: http://www.cno.org/learn-about-standards-guidelines/ educational-tools/nurse-practitioners/faqs-nurse-practitioners-andscope-of-practice/. Accessed April 13, 2015.

44. Canadian Nurse Association. Canadian Nurse Practititioner Core Competency Framework. Ontario: Canadian Nurse Association; 2010. Available from: http://www.cno.org/Global/for/rnec/pdf/CompetencyFramework_en.pdf. Accessed April 17, 2015.

45. Kaasalainen S, DiCenso A, Donald FC, Staples E. Optimising the role of the nurse practitioner to improve pain management in long-term care. CNJNR. 2007;39(2):14-31.

46. Kaasalainen S, Martin-Misener R, Carter N, DiCenso A, Donald FC, Baxter $\mathrm{P}$. The nurse practitioner role in pain management in long term care. JAdv Nurs. 2009;66(3):542-551.

47. Hughes F, Carryer J, editors. Nurse Practitioner in New Zealand. Wellington, New Zealand: Ministry of Health; 2002.

48. Hughes F, Lockyer H. Evidence and engagement in the introduction of nurse prescribing in New Zealand. Nurs Presc. 2004;2(3):131-136.

49. Nursing Council of New Zealand. Nurse Practitioner. Nursing Council of New Zealand; 2014 [cited April 13, 2015]. Available from: http://www.nursingcouncil.org.nz/Nurses/Scopes-of-practice/ Nurse-practitioner. Accessed April 13, 2015.

50. Lim AG, North N, Shaw J. Nurse prescribing: the New Zealand context. Nurs Prax N Z. 2014;30(2):18-27.

Nursing: Research and Reviews

\section{Publish your work in this journal}

Nursing: Research and Reviews is an international, peer-reviewed, open access journal publishing original research, reports, reviews and commentaries on all aspects of nursing and patient care. These include patient education and counselling, ethics, management and organizational issues, diagnostics and prescribing, economics and
51. Mackay B. General practitioners' perceptions of the nurse practitioner role: an exploratory study. $N Z$ Med J. 1170;2003:116.

52. Pirret AM. A critical care nurse practitioner's prescribing using standing orders and authorised prescribing when performing a critical care outreach role: a clinical audit. Intensive Crit Care Nurs. 2012;28(1):1-5.

53. Nursing and Midwifery Board Australia. Endorsement as a Nurse Practitioner Registration Standard; 2011 [updated March 2012; cited 2015 13/4/14]. Available from: http://www.nursingmidwiferyboard.gov.au/ Registration-and-Endorsement/Endorsements-Notations/Endorsementas-a-nurse-practitioner-registration-standard.aspx. Accessed April 13, 2015 .

54. Nursing and Midwifery Board Australia. Requirements for Portfolio Pathway 1; 2013 [updated December 17, 2013; cited April 17, 2015]. Available from: http://www.nursingmidwiferyboard.gov.au/ Registration-and-Endorsement/Endorsements-Notations/Requirementsfor-Portfolio-Pathway-1.aspx. Accessed April 17, 2015

55. Nursing and Midwifery Board Australia. Requirements for Portfolio Pathway 2; 2013 [updated December 17, 2013; cited April 17, 2015]. Available from: http://www.nursingmidwiferyboard.gov.au/ Registration-and-Endorsement/Endorsements-Notations/Requirementsfor-Portfolio-Pathway-2.aspx. Accessed April 17, 2015.

56. Gardner A, Gardner GE, Middleton S, Della PR. The status of Australian nurse practitioners: the first national census. Aus Health Rev. 2009;33(4):679-689.

57. NSW Health. Nurse Practitioners in NSW Guideline. NSW Health, Document no: GL2012_004; 2012. Available from: http:/www0.health. nsw.gov.au/policies/g1/2012/pdf/GL2012_004.pdf. Accessed April 15, 2015.

58. Scanlon A, Cashin A, Bryce J, Kelly J, Buckley TT. The complexities of defining nurse practitioner scope of practice in the Australian context. Collegian. In press 2015.

59. Cashin A. Collaborative arrangements for Australian nurse practitioners: a policy analysis. J Am Assoc Nurs Pract. 2014;26(10):550-554.

60. Khanal S, Buckley T, Harnden C, et al. Effectiveness of a national approach to prescribing education for multiple disciplines. $\mathrm{Br} \mathrm{J} \mathrm{Clin}$ Pharmacol. 2013;75(3):756-762.

61. Klein J. Five pitfalls in decisions about diagnosis and prescribing. Br Med J. 2005;330:781-783.

62. Cashin A, Stasa H, Dunn SV, Pont L, Buckley T. Nurse practitioner prescribing practice in Australia: confidence in aspects of medication management. Int J Nurs Pract. 2014;20(1):1-7.

63. Buckley T, Cashin A, Stuart M, Browne G, Dunn SV. Nurse practitioner prescribing practices: the most frequently prescribed medications. J Clin Nurs. 2013;22(13-14):2053-2063.

64. Murphy AL, Martin-Misener R, Cooke C, Sketris I. Administrative claims data analysis of nurse practitioner prescribing for older adults. J Adv Nurs. 2009;65(10):2077-2087.

65. Cashin A, Buckley T, Donoghue J, et al. Development of the Nurse Practitioner Standards for Practice Australia. Policy, Politics and Nursing Practice; 2015. Available from: http://ppn.sagepub.com/ content/early/2015/05/14/1527154415584233.full.pdf. resource management, health outcomes, and improving patient safety in all settings. The manuscript management system is completely online and includes a very quick and fair peer-review system. Visit http://www.dovepress.com/testimonials.php to read real quotes from published authors. 